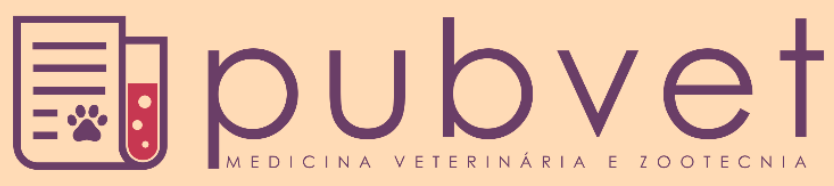

https://doi.org/10.31533/pubvet.v15n10a942.1-6

\title{
Hérnia perineal associada a divertículo retal em um cão: Relato de caso
}

\author{
Emanuel Tres Bernicker ${ }^{1 *}{ }^{\bullet}$, Andressa Spengler $^{2}{ }^{\circ}$, Andressa Antunes de Lima ${ }^{1}{ }^{\circ}$, Carolina \\ Andrade Romani ${ }^{10}$, Letícia Westphalen Trentin $^{10}$, Rafaela Lopes Manozzo $^{1}{ }^{\circ}$, Renato do \\ Nascimento Libardoni ${ }^{30}$ \\ ${ }^{I}$ Acadêmico de Medicina Veterinária, Universidade de Passo Fundo. Passo Fundo-RS Brasil. \\ ${ }^{2}$ Médica Veterinária Residente em Clínica Cirúrgica de Cães e Gatos do Hospital Veterinário/UPF. Passo Fundo-RS Brasil. \\ ${ }^{3}$ Orientador, Professor Mestre em Cirurgia e Clínica Veterinária da Universidade de Passo Fundo. Passo Fundo-RS Brasil. \\ *Autor para correspondência, emanuelbernicker@gmail.com
}

\begin{abstract}
Resumo. A hérnia perineal é um tipo de hérnia que acomete mais os caninos, principalmente os animais não castrados. A etiologia da mesma ainda é incerta, mas está relacionada a um enfraquecimento dos músculos do diafragma pélvico, acarretando a protrusão de órgão ou tecidos para a região perineal. Caracteriza-se pela presença de disquesia, constipação e aumento de volume na região perineal. O diagnóstico é basicamente clínico, através do toque retal e exames radiográficos ou ultrassonográficos, e o tratamento é através da correção cirúrgica. Atualmente, existem diversas técnicas descritas para a correção de hérnias perineais, contudo as que utilizam transposições musculares apresentam maior eficiência. $\mathrm{O}$ objetivo desse trabalho é relatar um caso de hérnia perineal associada a divertículo retal do lado direito em um canino. A correção do defeito foi através da herniorrafia perineal com transposição do músculo obturador interno associada a plicatura das camadas muscular e serosa retal para a correção do divertículo.
\end{abstract}

Palavras-chave: Caninos, correção cirúrgica, divertículo retal, hérnia perineal, prognóstico

\section{Perineal hernia associated with a right rectal diverticulum in a dog: Case report}

\begin{abstract}
Perineal hernia is a type of hernia that affects more canines, especially noncastrated animals. Its etiology is still uncertain, but it is related to a weakening of the pelvic diaphragm muscles, resulting in the protrusion of organs or tissues to the perineal region. It is characterized by the presence of dyskinesia, constipation and swelling in the perineal region. The diagnosis is basically clinical, through digital rectal examination and radiographic or ultrasound exams, and the treatment is through surgical correction. Currently, there are several techniques described for the correction of perineal hernias, however those that use muscle transpositions are more efficient. The aim of this study is to report a case of perineal hernia associated with a right rectal diverticulum in a canine. The defect was corrected through perineal herniorrhaphy with transposition of the internal obturator muscle associated with plication of the muscular and serous rectal layers for the correction of the diverticulum.
\end{abstract}

Keywords: Canines, surgical correction, rectal diverticulum, perineal hernia, prognosis

\section{Hernia perineal asociada a divertículo rectal derecho en un perro: Reporte de caso}

Resumen. La hernia perineal es un tipo de hernia que afecta a más caninos, especialmente a animales no castrados. Su etiología aún es incierta, pero se relaciona con un 
debilitamiento de la musculatura del diafragma pélvico, lo que resulta en la protrusión de órganos o tejidos hacia la región perineal. Se caracteriza por la presencia de discinesia, estreñimiento e hinchazón en la región perineal. El diagnóstico es básicamente clínico, mediante tacto rectal y exámenes radiográficos o ecográficos, y el tratamiento es mediante corrección quirúrgica. Actualmente, existen varias técnicas descritas para la corrección de las hernias perineales, sin embargo, las que utilizan transposiciones musculares son más eficientes. El objetivo de este estudio es reportar un caso de hernia perineal asociada a divertículo rectal derecho en un canino. El defecto se corrigió mediante herniorrafia perineal con transposición del músculo obturador interno asociada a plicatura de las capas muscular y rectal serosa para la corrección del divertículo.

Palabras clave: Caninos, corrección quirúrgica, divertículo rectal, hernia perineal, pronóstico

\section{Introdução}

As hérnias são afecções cirúrgicas comuns na rotina clínico-cirúrgica de cães e gatos, sendo definida como a protrusão de um órgão ou tecido por um defeito na parede da cavidade anatômica, podendo ser classificadas em hérnias verdadeiras e falsas. A hérnia verdadeira é constituída pelo saco herniário, anel herniário e conteúdo herniário e são nomeadas conforme a localização anatômica (Chevrel \& Rath, 2000). A hérnia perineal é a mais comum em cães, acometendo principalmente as raças Collies, Boxers, Boston Terrier, Poodle, Pequinês, Dachshunds, Pastor Alemão e cães sem raça definida, sendo rara em cadelas e gatos (Assumpção et al., 2016; Matera et al., 1981). Os sinais clínicos que caracterizam essa afecção incluem disquesia, constipação e aumento de volume na região perineal uni ou bilateral. Para seu diagnóstico, indica-se o toque retal, com o intuito de detectar o anel herniário, desvio do reto ou formação de divertículo retal, além de exames de imagem radiográficas e ultrassonográficas, as quais auxiliam no diagnóstico e são úteis para definir o volume e eventuais complicações da hérnia (Fossum, 2014; Nelson \& Couto, 2015; Raiser, 2017). O tratamento definitivo é cirúrgico, podendo ser emergencial quando apresentar encarceramento e estrangulamento de órgãos, principalmente quando a bexiga urinária estiver acometida, podendo, desencadear uremia pós-renal grave e potencialmente fatal (Chevrel \& Rath, 2000). O objetivo deste trabalho é relatar um caso de hérnia perineal associada a divertículo retal do lado direito em um canino.

\section{Relato do caso clínico}

Foi atendido um canino, macho, sem raça definida, de cinco anos de idade, não castrado, pesando 30 $\mathrm{kg}$, apresentando disquesia e aumento de volume na região perineal direita com evolução de 10 dias e, estar apresentando fezes de consistência amolecida durante os três dias que antecederam o atendimento. No exame físico, apresentou parâmetros vitais normais para a espécie, algia à palpação abdominal, aumento de volume na região perineal direita (Figura 1) e, mediante palpação retal digital, constatou-se a presença de defeito caracterizado como anel herniário e um defeito na parede retal caracterizada como divertículo retal.

Incialmente foram realizados exames hematológicos, como hemograma completo e bioquímica sérica para avaliação hepática e renal, além de radiografia abdominal simples e contrastada. No leucograma, evidenciou-se leucocitose $(24.000 / \mathrm{uL})$ por neutrofilia $(22.320 \mu \mathrm{L})$ e linfopenia $(720 \mu \mathrm{L})$. Nos bioquímicos, a albumina estava levemente aumentada $(36,90 \mathrm{~g} / \mathrm{L})$ e a ureia levemente diminuída $(16,34 \mathrm{mg} / \mathrm{dL})$. Na radiografia abdominal simples foi evidenciado cólon e reto repletos de fezes endurecidas. Após realização de enema para evacuação do reto, foi realizado radiografia contrastada, evidenciando a presença de divertículo retal. Com base nas informações do exame clínico e exames complementares, diagnosticamos hérnia perineal unilateral direita com divertículo retal associado.

O cão foi internado para estabilização clínica e preparo pré-operatório, para tanto, o mesmo foi submetido a fluidoterapia com solução de ringer com lactato $(5 \mathrm{ml} / \mathrm{kg} / \mathrm{hora})$ e tratamento com lactulona (1 $\mathrm{ml} / 4,5 \mathrm{~kg}$, BID, VO), metronidazol 0,5\% (15 mg/kg, BID, IV), óleo mineral (1 ml $/ \mathrm{kg}, \mathrm{BID}, \mathrm{VO})$, dipirona $(25 \mathrm{mg} / \mathrm{kg}$, TID, IV) e alimentação pastosa. Após cinco dias, obtivemos estabilização clínica e diminuição dos sinais clínicos. Diante disso, o paciente foi encaminhado para procedimento cirúrgico de herniorrafia perineal mediante a técnica de transposição do músculo obturador interno associado à plicatura retal para a correção do divertículo. 
Na avaliação pré-anestésica, não apresentou alteração nos parâmetros fisiológicos. Foi pré-medicado com acrepromazina $(0,03 \mathrm{mg} / \mathrm{kg})$, midazolam $(0,1 \mathrm{mg} / \mathrm{kg})$, metadona $(0,3 \mathrm{mg} / \mathrm{kg})$ e cetamina $(1 \mathrm{mg} / \mathrm{kg})$, pela via intramuscular. Em seguida, foi submetido a tricotomia ampla da região perineal e cauda. Indução anestésica com propofol $(4 \mathrm{mg} / \mathrm{kg}$, IV), intubação orotraqueal para a manutenção anestésica com isoflurano vaporizado em oxigênio a $100 \%$. E, bloqueio epidural com lidocaína $(0,1 \mathrm{ml} / \mathrm{kg})$, bupivacaína $(0,1 \mathrm{ml} / \mathrm{kg})$ e morfina $(0,1 \mathrm{mg} / \mathrm{kg})$, além de profilaxia antimicrobiana com cefalotina (25 $\mathrm{mg} / \mathrm{kg} / \mathrm{IV})$.

O cão foi posicionado em decúbito esternoabdominal, com os membros pélvicos pendentes em uma das extremidades da mesa cirúrgica e a cauda tracionada dorsocranialmente. Em seguida, foi realizada sutura em bolsa de tabaco no ânus para evitar extravasamento fecal e executada a antissepsia prévia da região com clorexidina degermante $2 \%$, retirado o excedente da solução com álcool $70 \%$. A antissepsia definitiva foi realizada pelo cirurgião, utilizando clorexidina alcóolica $0,5 \%$. Procedeu-se com uma incisão de pele sobre a região herniária perianal direita, da base da cauda até o ângulo medial da tuberosidade isquiática, em seguida, realizou-se a incisão e divulsão do saco herniário (Figura 2A), identificação da bexiga urinária herniada e o reto com divertículo (Figura 2B). Para facilitar a identificação do divertículo, realizou-se a insuflação do reto com $60 \mathrm{~mL}$ de ringer lactato, o qual apresentou aproximadamente três $\mathrm{cm}$ (Figura 3A). Foram realizados quatro pontos de plicatura abrangendo as camadas serosa e muscular (Figura 3B), com sutura padrão Lembert interrompido, para a redução do lúmen do divertículo, utilizando fio de poliamida tamanho 3-0.

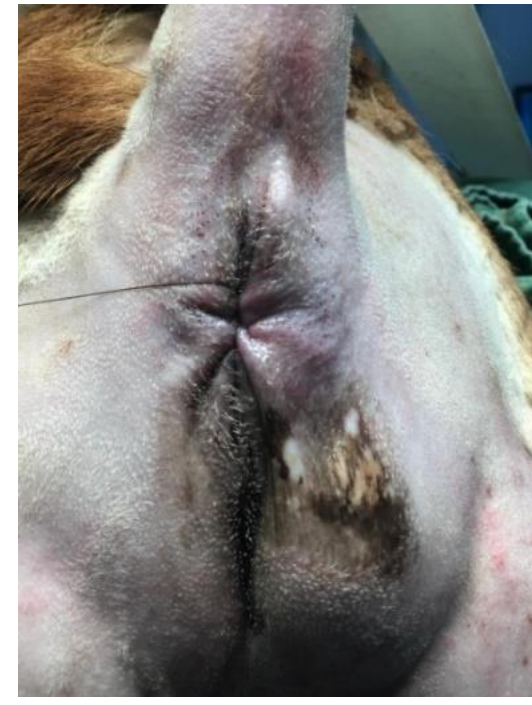

Figura 1. Aumento de volume no lado direito do ânus.

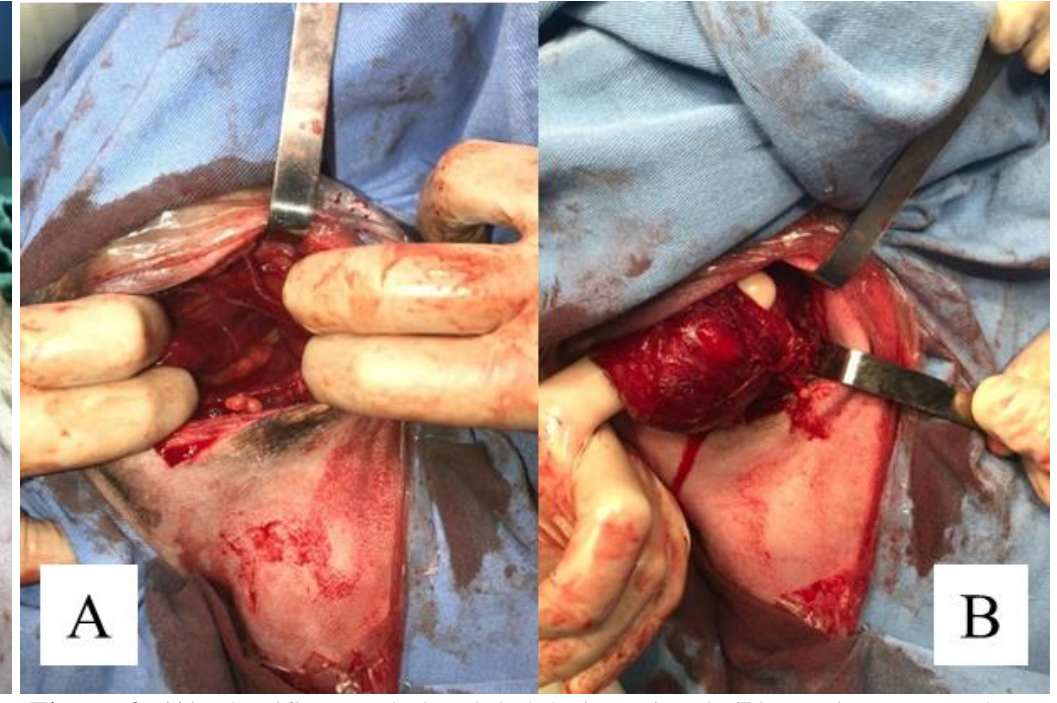

Figura 2. (A) Identificação do local da hérnia perineal. (B) Tracionamento do reto para identificação do divertículo

Após a correção do divertículo, realizou-se a herniorrafia, com a aplicação de suturas isoladas simples entre os músculos coccígeos e esfíncter anal externo utilizando fio de poliamida tamanho 0 , para conferir maior sustentação e vascularização adicional para a cicatrização. Realizada a secção do músculo obturador interno na sua borda caudolateral e descolado da tábua do ísquio, este foi rebatido dorsalmente na sua borda medial e suturado ao músculo esfíncter externo do ânus e a borda dorsolateral ao músculo coccígeo e ao ligamento sacrotuberal, utilizando fío de poliamida tamanho 0 em padrão isolado simples e Wolff (Figura 4A). A redução do tecido subcutâneo foi realizada com fio de poliglecaprone- $25 \mathrm{n}^{\circ} 2.0$ em padrão simples contínuo e a dermorrafia com fio de poliamida tamanho 30 em padrão Wolff (Figura 4B).

Durante a internação pós-cirúrgica, foi mantido o uso de lactulona, metronidazol 0,5\%, óleo mineral e dipirona nas mesmas doses e frequências utilizadas no pré-cirúrgico, e adicionado ao tratamento meloxicam $(0,1 \mathrm{mg} / \mathrm{kg}$, SID, IV), cefalotina ( $25 \mathrm{mg} / \mathrm{kg}$, TID, IV), metadona (0,3 mg/kg, TID, SC), além de cuidados como limpeza da ferida cirúrgica, alimentação pastosa e uso de colar elizabetano.

Após dois dias do pós-operatório e novos exames de sangue, sem alterações dignas de nota o paciente obteve alta médica. Sendo prescrito para tratamento em casa omeprazol (1 mg/kg, VO, SID) 
sulfadimetoxima e ormetoprim ( $80 \mathrm{mg} / \mathrm{kg}$, VO, SID), tramadol (4 mg/kg, VO, TID), dipirona ( $2 \mathrm{mg} / \mathrm{kg}$, VO, TID), meloxicam $(0,1 \mathrm{mg} / \mathrm{kg}, \mathrm{VO}, \mathrm{SID})$, óleo mineral (1 ml/kg, VO, BID) e fornecer somente alimentação pastosa, devendo retornar para nova avaliação em sete dias.

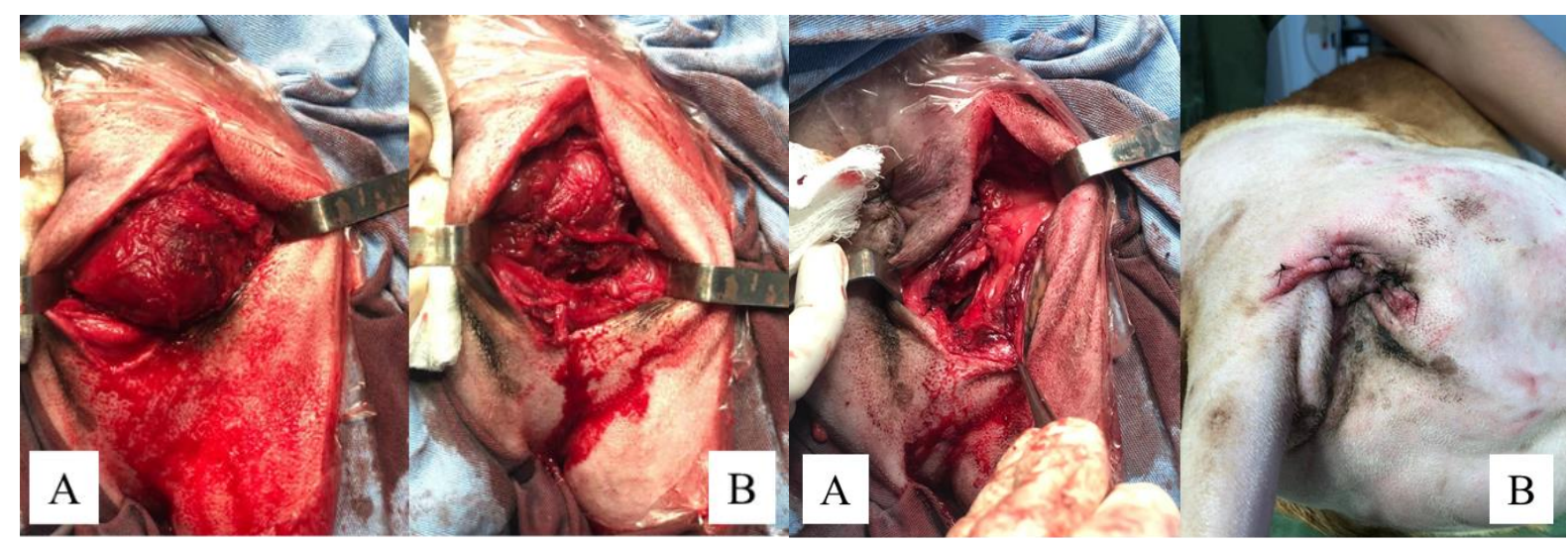

Figura 3. (A) Insuflação do reto para confirmação do local do divertículo. (B) Aspecto após realizar as suturas de plicatura do divertículo.
Figura 4. (A) Resultado final da herniorrafia perineal. (B) Pós-operatório imediato.

Em relação aos cuidados pós-operatórios com o paciente em casa, foram instruídos a realizar higienização dos pontos duas vezes ao dia, lavar a ferida com ducha caso sujasse com fezes, manter em uso do colar elisabetano, não permitir que o animal coce e/ou lamba os pontos, manter em repouso em ambiente quente, limpo, seco e fechado até a remoção dos pontos, manter a alimentação com ração pastosa nos primeiros cinco dias. Todos esses cuidados foram fundamentais para a recuperação e melhora do paciente sem complicações.

Na reavaliação do paciente após 10 dias do procedimento cirúrgico para retirada dos pontos, foi relatado pelos tutores que o paciente se exibia bem clinicamente e que apresentava fezes pastosas, sem sinais clínicos como diarreia ou constipação, também informaram que do tratamento instituído para casa, não administraram o antibiótico (sulfametoxima e ormetoprim), mas apesar da não administração do fármaco a ferida cirúrgica estava plenamente cicatrizada e os pontos foram removidos.

\section{Discussão}

A hérnia perineal tem causas ainda indefinidas, mas acredita-se que esteja relacionado a uma ação hormonal, esforço físico, fraqueza ou atrofia muscular. Esses fatores causam o enfraquecimento dos músculos do diafragma pélvico, não sustentando mais a parede retal (Raiser, 2017). A prevalência dessa afecção é em cães machos não castrados (93\%) e com mais de cinco anos de idade (Assumpção et al., 2016; Fossum, 2014). Associada a hérnia, ocorre a compactação das fezes no canal, podendo levar a um aumento de pressão na parede retal e formação de um divertículo retal, que se caracteriza pela protrusão da mucosa através do defeito da parede (Fossum, 2014). O divertículo retal é uma condição considerada grave e, se não tratada durante a correção da hérnia, pode ocorrer perda de reparo da herniorrafia, predispondo à recorrência da herniação (Costa Neto et al., 2006; Moraes et al., 2013).

O presente estudo relata um caso de hérnia perineal associada a divertículo retal direito. A escolha da técnica aplicada foi determinada pela experiência do cirurgião e por permitir realizar a correção do divertículo retal durante o mesmo procedimento, uma vez que a existência de anomalias como o divertículo compromete a eficácia herniorrafia perineal (Bellenger, 1980). A técnica de transposição do músculo obturador interno é considerada mais difícil se comparada às outras técnicas, no entanto ela confere maior reforço à porção ventral da hérnia, provoca menos tensão em suturas, causa menor deformação do ânus, oferece vascularização adicional para a cicatrização, além de diminuir as taxas de recidivas (Assumpção et al., 2016; Fossum, 2014). A realização da orquiectomia durante a herniorrafia é indicada por haver indícios de reduzir os casos de recidivas; porém, por decisão dos tutores, este procedimento não foi realizado, podendo interferir no resultado duradouro da cirurgia. Estudos demonstram que cães castrados apresentam uma taxa de recidiva 2,7 vezes menor quando comparado a cães inteiros (Fossum, 2014). 
A escolha das medicações utilizadas durante o período de internação foi baseada nos sinais clínicos e no quadro do paciente. A associação ormetoprima + sulfadimetoxina é usada em pequenos animais para tratar uma variedade de infecções bacterianas por apresentar ação bactericida e bacteriostática, espectro antibacteriano amplo, incluindo bactérias comuns gram-positivas e gram-negativas, além de atuar contra alguns coccídios. A necessidade de associar dois antibióticos tem o intuito de reduzir os riscos de infecção pós-operatória e também considerando a contaminação que a ferida cirúrgica está sujeita devido a proximidade com o ânus. Adicionalmente, o uso de anti-inflamatório não esteroidal, analgésico visceral e analgésico opióide proporcionaram conforto ao animal, reduzindo a dor pósoperatória, o edema e a disquesia, além de auxiliar na cicatrização da ferida cirúrgica. A alimentação pastosa, a administração de laxante osmótico e emoliente são fornecidos com o intuito de facilitar o trânsito gastrointestinal, evitando o esforço ao defecar, que pode predispor a recidiva da hérnia (Andrade, 2011).

A presença de leucocitose branda por neutrofilia sem desvio à esquerda e linfopenia no leucograma pré-operatório e a presença de leucocitose branda por neutrofilia com desvio à direita (neutrófilos hipersegmentados) e monocitose no pós-operatório são indicadores de estresse crônico (Laurino, 2009). Esse estresse provavelmente está relacionado ao período de dez dias que o animal permaneceu apresentando os sinais clínicos de disquesia. Em situações de estresse, os corticoides reduzem a passagem dos leucócitos do sangue para os tecidos (diapedese), fazendo com que aumente o número dessas células no sangue periférico. Além disso, esse hormônio também causa linfólise e diminui a recirculação dos linfócitos, resultando em linfopenia. Neutrófilos hipersegmentados são células que estão na circulação há mais tempo e apresentam mais de cinco segmentos nucleares. A presença dessas "células velhas" associada a leucocitose, indica aumento na produção de corticoides endógenos ou exógenos. Isso se deve ao fato de que os corticoides prejudicam a diapedese dessas células, o que explica o envelhecimento dos mesmos na corrente sanguínea (Garcia-Navarro \& Pachaly, 1994; Kantek \& Navarro, 2005). O aumento dos monócitos, resposta que ocorre particularmente em cães, acompanha as outras características hematológicas e surge porque os corticoides causam desmarginação dos leucócitos do compartimento marginal para o compartimento circulante (Garcia-Navarro \& Pachaly, 1994; Kantek \& Navarro, 2005; Silva et al., 2008).

Por meio de uma técnica cirúrgica correta e manejo do paciente no pós-operatório, a maioria das complicações pós-operatórias podem ser prevenidas. No caso em específico do paciente desse relato, não houve a presença de complicações, o que confere um bom prognóstico para o mesmo. Dentre as complicações que podem ser observadas em pós-operatórios de herniorrafias perineais e correções de divertículos retais destacam-se: recidivas, infecção do sítio cirúrgico, deiscência de sutura, compressão do nervo ciático, hemorragia, incontinência fecal e tenesmo, disquesia, prolapso retal, disfunção urinária, entre outros (Fossum, 2014; Raiser, 2017).

\section{Conclusão}

O diagnóstico definitivo da hérnia perineal foi possível mediante exame físico e palpação retal digital juntamente com os exames de imagem. A herniorrafia perineal mediante técnica de transposição do músculo obturador interno foi eficaz. O divertículo retal pode estar associado à hérnia perineal, e o exame de palpação retal digital e radiografia contrastada confirmam o diagnóstico. O tratamento do divertículo mediante técnica de plicatura seromuscular foi eficaz no paciente deste relato.

\section{Referências bibliográficas}

Andrade, S. F. (2011). Manual de terapêutica veterinária. Editora Roca.

Assumpção, T. C. A., Matera, J. M., \& Stopiglia, A. J. (2016). Herniorrafia perineal em cães-revisão de literatura. Revista de Educação Continuada Em Medicina Veterinária e Zootecnia Do CRMV-SP, 14(2), 12-19. https://doi.org/10.36440/recmvz.v14i2.31813.

Bellenger, C. R. (1980). Perineal hernia in dogs. Australian Veterinary Journal, 56(9), 434-438.

Chevrel, J. P., \& Rath, A. M. (2000). Classification of incisional hernias of the abdominal wall. Hernia, $4(1), 7-11$.

Costa Neto, J. M., Menezes, V. P., Toribio, J., Oliveira, E. C. S., Anunciação, M. C., Teixeira, R. G., 
D’Assis, M., \& Vieira Júnior, A. S. (2006). Tratamento cirúrgico para correção de hérnia perineal em cão com saculação retal coexistente. Revista Brasileira de Produção e Saúde Animal, 7(1), 7-19.

Fossum, T. W. (2014). Cirurgia de pequenos animais (4th ed., Vol. 1). Elsevier Brasil.

Garcia-Navarro, C. E., \& Pachaly, J. R. (1994). Manual de hematologia veterinária (Vol. 1). Varela.

Kantek, C. E., \& Navarro, K. G. (2005). Manual de Hematologia Veterinária. São Paulo: Varela, 2. ed., $206 \mathrm{p}$.

Laurino, F. (2009). Alterações hematológicas em cães e gatos sob estresse. Universidade Estadual Paulista, 21p. http://hdl.handle.net/11449/119576

Matera, A., Moraes Barros, P. S., Stopiglia, A. J., \& Randi, R. E. (1981). Hérnia perineal no cão. Tratamento cirúrgico mediante utilização de malha de polipropileno. Revista Da Faculdade de Medicina Veterinária e Zootecnia Da Universidade de São Paulo, 18(1), 37-41.

Moraes, P. C., Zanetti, N. M., Burger, C. P., Meirelles, A. E. W. B., Canola, J. C., \& Isola, J. G. M. P. (2013). Correction of rectal sacculation through lateral resection in dogs with perineal herniatechnique description. Arquivo Brasileiro de Medicina Veterinária e Zootecnia, 65(3), 654-658.

Nelson, R. W., \& Couto, C. G. (2015). Medicina interna de pequenos animais (Issue 1). Elsevier Editora.

Raiser, A. (2017). Herniorrafia perineal em defeitos extensos e com pouca sustentação. In M. W. Brun (Ed.), Cirurgias complexas em pequenos animais. Payá.

Silva, R., Almeida Júnior, G. S., Cury, J. R. M., Amaral, R. A., Perenha, R. A., Locatelli, L., Matias, V., \& Sacco, S. R. (2008). Leucograma de estresse. Revista Científica Eletrônica de Medicina Veterinária, 4, 1-4.

Histórico do artigo:

Recebido: 21 de junho de 2021

Aprovado: 19 de julho de 2021
Licenciamento: Este artigo é publicado na modalidade Acesso Aberto sob a licença Creative Commons Atribuição 4.0 (CC-BY 4.0), a qual permite uso irrestrito, distribuição, reprodução em qualquer meio, desde que o autor e a fonte sejam devidamente creditados. 